\title{
STUDI PERBANDINGAN ANALISIS VITAMIN E MINYAK SAWIT MERAH TERSAPONIFIKASI ANTARA METODE SPEKTROFOTOMETRI UV-VIS DAN KCKT
}

\section{[Comparative Study of Spectrophotometry UV- Vis and HPLC Method for the Analysis of Vitamin E in Saponified Red Palm Oil]}

\author{
Arlina Mayharty Andulaa ${ }^{1}$, Ruslan ${ }^{{ }^{\star}}{ }^{\star}$, Hardi Ys ${ }^{1}$, Dwi Juli Puspitasari ${ }^{1}$ \\ 1) Jurusan Kimia, Fakultas Matematika dan Ilmu Pengetahuan Alam, Universitas Tadulako \\ Jl. Soekarno Hatta, Kampus Bumi Tadulako Tondo Palu, Telp. 0451- 422611
}

Diterima 28 Desember 2016, Disetujui 21 Februari 2017

\begin{abstract}
A research about a comparative study of spectrophotometry UV-Vis and HPLC method for the analysis of vitamin $E$ in saponified red palm oil has been done. This research aims to compare the results of analysis using Spectrophotometer UV - Vis and HPLC to determine the concentration of vitamin $E$ in red palm oil previously saponified and extracted. HPLC analysis was carried out using an RP-18 column and mobile phase composed a methanol and water ( 86:14), with a flow rate of 1 $\mathrm{ml} / \mathrm{min}$ and UV detection at $290 \mathrm{~nm}$. For the Spectrophotometric UV-Vis analysis, hexane was used as a solvent and the wavelength at $298,5 \mathrm{~nm}$ was selected for the detection. The results are the concentration of vitamin E using spectrophotometric and HPLC method was respectively 104.5 ppm and $127 \mathrm{ppm}$.
\end{abstract}

Keyword: Vitamin E, Red Palm Oil, saponification, extraction, spectrophotometry Ultra Violet -Visible, High Performance Liquid Chromatography

\begin{abstract}
ABSTRAK
Telah dilakukan penelitian tentang Studi Perbandingan Analisis Vitamin E Minyak Sawit Merah Tersaponifikasi Antara Metode Spektrofotometri UV-Vis Dan KCKT. Penelitian ini bertujuan untuk membandingkan hasil analisis menggunakan spektrofotometer UV-Vis dan KCKT dalam menentukan konsentrasi vitamin $\mathrm{E}$ dalam minyak sawit merah yang sebelumnya telah disaponifikasi dan diekstraksi. Analisis dengan metode KCKT menggunakan kolom fase terbalik, fase gerak yang digunakan merupakan campuran metanol dan air (86:14), laju alir $1 \mathrm{ml} / \mathrm{menit}$ dan dianalisis pada panjang gelombang UV $290 \mathrm{~nm}$. Analisis Spektrofotometri UV-Vis, menggunakan heksan sebagai pelarut dan dianalisis pada panjang gelombang $298,5 \mathrm{~nm}$. Konsentrasi vitamin E hasil analisis dengan Spektrofotometri UV-Vis dan KCKT berturut-turut sebesar 104,5 ppm dan 127 ppm.
\end{abstract}

Kata Kunci : Vitamin E, Minyak Sawit Merah, Saponifikasi, Ekstraksi, Spektrofotometri Ultra VioletVisibel, Kromatografi Cair Kinerja Tinggi 


\section{LATAR BELAKANG}

Vitamin $\mathrm{E}$ termasuk dalam vitamin yang larut dalam lemak dan berfungsi sebagai antioksidan. Vitamin E terbagi menjadi beberapa isomer, yaitu struktur $\alpha$ tokoferol, $\beta$ - tokoferol, $\gamma^{-}$tokoferol, $\delta$ tokoferol, dan tokotrienol (Świglo et al., 2007). Tumbuhan yang kaya lemak atau minyak nabati, seperti kelapa sawit, gandum, dan beras katul adalah sumber utama vitamin E. Sumber lainnya yang hanya mengandung tokoferol berupa sereal, bunga matahari, minyak zaitun, dan kacang (Bonnie \& Choo, 2000).

Minyak sawit merah (Red Palm Oil/RPO) merupakan salah satu produk dari pengolahan minyak sawit mentah yang mengandung karoten dan vitamin $\mathrm{E}$ yang cukup tinggi (Ooi et al., 1991). Choo et al. (1993) melaporkan bahwa isomer vitamin $E$ yang terdapat dalam minyak sawit merah adalah $\alpha$-tokoferol $(\alpha-T)$, $\alpha$ tokotrienol $\left(\alpha-T_{3}\right), y$-tokotrienol $\left(\gamma-T_{3}\right)$ dan $\delta$-tocotrienol $\left(\delta-T_{3}\right)$. Dauqan et al. (2011) melaporkan bahwa kandungan vitamin $\mathrm{E}$ dalam minyak sawit merah berturut-turut sebagai berikut $\alpha$-tokoferol sebesar 171 ppm, $\alpha$-tokotrienol $\left(\alpha-T_{3}\right)$ sebesar 294 ppm, $\mathrm{Y}$-tokotrienol $\left(\mathrm{\gamma}-\mathrm{T}_{3}\right)$ sebesar $367 \mathrm{ppm}$ dan $\delta$-tocotrienol $\left(\delta-T_{3}\right)$ sebesar 126 ppm. Penentuan vitamin $\mathrm{E}$ dapat dilakukan dengan menggunakan Kromatografi Cair Kinerja Tinggi (KCKT) dan Spektrofotometer Uv-Vis.

KCKT adalah metode yang banyak digunakan untuk menetapkan tokoferol dan tokotrienol dalam sediaan makanan maupun nutrisi lainnya. Semua bentuk tokoferol dan tokotrienol dapat dipisahkan dan ditetapkan kadarnya dengan metode KCKT baik dengan menggunakan kolom fase normal maupun fase terbalik (Lampi, 2013). Meskipun demikian, KCKT memiliki kekurangan antara lain biaya analisis yang relatif mahal dan membutuhkan keterampilan khusus dalam proses pengoperasiannya, sehingga dibutuhkan suatu metode yang dapat menganalisis vitamin $\mathrm{E}$ dengan peralatan yang mudah diperoleh dan biaya analisisnya lebih ekonomis. Sementra itu, spektrofotometri UV-Vis merupakan instrumen yang paling sering digunakan di laboratorium kimia analisis, salah satunya untuk menentukan konsentrasi suatu senyawa tunggal maupun campuran (Rohman, 2007).

Oleh karena itu, perlu dilakukan penelitian untuk membandingkan antara metode Spektrofotometri UV-Vis dan KCKT dalam menentukan konsentrasi vitamin $E$ dalam sampel minyak sawit merah yang telah tersaponifikasi.

\section{METODE PENELITIAN}

\section{Bahan dan Peralatan}

Bahan yang digunakan dalam penelitian ini adalah minyak sawit merah yang diperoleh dari laboratorium penelitian Jurusan Kimia FMIPA Untad, standar vitamin $\mathrm{E}$ yaitu a-tokoferol (Merck) (>96\%), etanol $95 \%$, natrium hidroksida, antioksidan BHT (Butil Hidroksi Toluen), 2-propanol, heksan, metanol, akuades, natrium klorida. 
Alat yang digunakan adalah seperangkat alat spektrofotometer UV-Vis (Cecil CE 20212000 Series), kuvet, mikropipet, peralatan gelas yang umum digunakan di laboratorium, penangas air, corong pisah, neraca analitik, seperangkat alat KCKT.

\section{Prosedur Penelitian}

\section{Saponifikasi Minyak Sawit Merah dan Ekstraksi Vitamin E}

Sebanyak $20 \mathrm{~mL}$ minyak sawit merah disaponifikasi selama 45 menit dalam erlenmeyer tertutup dengan penambahan $20 \mathrm{~mL}$ etanol (95\%), $60 \mathrm{~mL}$ $\mathrm{NaOH}$ 0,25 M dan $50 \mathrm{~mL}$ BHT 0,3 M. Erlenmeyer ditempatkan dalam penangas air suhu $70^{\circ} \mathrm{C}$ dan dikocok setiap $5-10$ menit selama proses saponifikasi. Setelah proses saponifikasi, erlenmeyer didinginkan dalam penangas es dan ditambahkan $150 \mathrm{~mL} \quad \mathrm{NaCl} \quad 0,02 \mathrm{M}$ (Kresnawaty, et al., 2012). Hasil saponifikasi dimasukkan ke dalam corong pemisah, bagian atas adalah fraksi minyak yang tak tersabunkan, di tengah adalah fraksi minyak yang tersabunkan dan bagian bawah adalah fraksi air (ESA, 2002). Selanjutnya, fraksi yang tak tersabunkan ditambahkan dengan $70 \mathrm{ml}$ metanol dan didiamkan hingga terbagi menjadi dua fraksi. Bagian atas diambil ditambahkan dengan $20 \mathrm{~mL}$ 2-propanol (1\%) dalam heksana (Kresnawaty et al., 2012).. Fraksi yang larut heksan (bagian atas) diambil untuk analisis dengan Spektrofotometer UV-Vis dan KCKT.

\section{Analisis Vitamin E dengan Metode Spektrofotometri UV-Vis}

a. Pembuatan Larutan Induk Standar Vitamin E Konsentrasi 100 ppm

Menimbang 0,01 g vitamin E murni, melarutkannya dengan heksan dan memasukkan ke dalam labu ukur 100 mL dan ditambahkan heksan hingga tanda batas.

\section{b. Pembuatan Seri Larutan Standar}

Mengencerkan larutan standar induk 100 ppm dengan heksan pada masingmasing labu ukur $25 \mathrm{~mL}$ dengan konsentrasi 12,5; 17,5; 25 dan 50 ppm.

\section{c. Penentuan Panjang Gelombang Maksimum}

Larutan baku diukur absorbansinya untuk menentukan panjang gelombang maksimum pada kisaran 280 - 328 nm menggunakan spektrofotometer UV-Vis. Panjang gelombang maksimum yang diperoleh ditentukan dari nilai absorban tertinggi.

\section{d. Pembuatan Kurva Standar}

Mengukur absorbansi seri larutan standar 12,5; 17,5; 25 dan 50 ppm pada panjang gelombang maksimum kemudian dibuat kurva baku, dimana absorban sebagai ordinat dan konsentrasi sebagai absis. Dari kurva baku ini diperoleh persamaan linear $y=a x+b$.

\section{e. Penentuan Konsentrasi Sampel}

Melakukan pengukuran absorbansi terhadap ekstrak vitamin $\mathrm{E}$ hasil ekstraksi. Nilai absorbansi yang diperoleh digunakan untuk menghitung konsentrasi vitamin $\mathrm{E}$ dengan menggunakan persamaan garis linear regresi dari kurva kalibrasi/standar 
yang telah dibuat sehingga bisa diketahui konsentrasi sampel minyak sawit merah.

\section{Analisis Vitamin E Menggunakan KCKT}

\section{a. Pembuatan larutan standar}

Larutan induk diencerkan dengan metanol hingga diperoleh deret larutan standar 0,$25 ; 0,5 ; 2,5 ; 5,0 ; 25,0$ dan 50,0 ppm kemudian disaring dengan PTFE 0,45 $\mu \mathrm{m}$ dan diinjeksikan ke sistem KCKT.

\section{b. Pengerjaan sampel}

Sebanyak 5 gram sampel yang telah dihomogenkan dimasukkan ke dalam Erlenmeyer $100 \mathrm{~mL}$ dan menambahkan etanol $95 \%$ sebanyak $40 \mathrm{~mL}$. Kemudian menambahkan asam pirogalat sebanyak $50 \mathrm{mg}$ dan dilewatkan gas nitrogen sebelum dipanaskan. Setelah itu menambahkan $\mathrm{KOH} 50 \%$ sebanyak 10 $\mathrm{mL}$. larutan kemudian dikocok dan dipanaskan dalam waterbath pada suhu $\pm 80^{\circ} \mathrm{C}$ selama 45 menit dan dikocok setiap 10 menit. Setelah larutan dingin, ditambahkan dengan asam asetat glacial dan didinginkan kembali hingga suhu ruang. Kemudian memasukkan ke dalam labu ukur $100 \mathrm{~mL}$ dan himpitkan larutan dengan THF-etanol 95\% (1:1) dan homogenkan. Setelah itu didiamkan hingga 1 jam pada suhu ruang. Larutan tersebut kemudian disaring dengan PTFE $0,45 \mu \mathrm{m}$ dan diinjeksikan ke sistem KCKT.

Perhitungan kadar Vitamin E dalam sampel dengan menggunakan kurva kalibrasi standar dengan persamaan garis: $y=b x+a$, dengan rumus sebagai berikut :
Konsentrasi Vitamin $\mathrm{E}(\mathrm{ppm})=\frac{\frac{A s p l-a}{b} \times f p \times 10}{V \text { spl }}$ Keterangan:

A.spl = Luas area sampel

a = intersep dari kurva kalibrasi standar

b = slope dari kurva kalibrasi standar

$\mathrm{fp} \quad=$ faktor pengenceran sampel

\section{HASIL DAN PEMBAHASAN}

\section{Hasil Saponifikasi Minyak Sawit Merah Dan Ekstraksi Vitamin E}

Hasil saponifikasi dan ekstraksi dapat dilihat pada gambar 1 berikut.

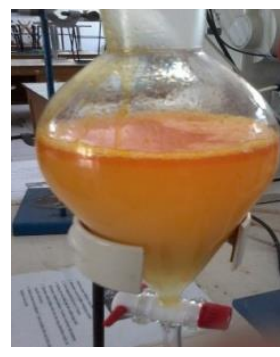

(a)

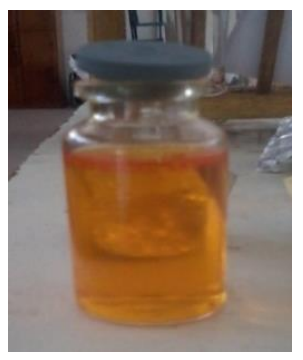

(b)
Gambar 1 (a) Hasil Saponifikasi Minyak Sawit Merah, (b) Hasil Ekstraksi Vitamin E

Saponifikasi dan ekstraksi dilakukan untuk memisahkan komponen tersaponifikasi yang dapat mempengaruhi determinasi vitamin E. Pada tahap saponifikasi, pemanasan pada suhu $70^{\circ} \mathrm{C}$ dilakukan untuk mempercepat reaksi. Ini merupakan kondisi optimal karena suhu yang lebih tinggi dan waktu yang relatif lama akan merusak isomer vitamin $E$ (Ryynanen et al., 2004; Lampi, 2013; Martha et al., 2012) sedangkan waktu yang relatif singkat menyebabkan penurunan tingkat regenerasi isomer (Martha et al., 2012). Penambahan BHT berfungsi mencegah oksidasi vitamin $E$ oleh udara, maupun oleh pemanasan dan $\mathrm{NaCl}$ berfungsi mengendapkan sabun 
sehingga mudah dipisahkan antara fraksi tersabunkan, fraksi tidak tersabunkan dan fraksi air.

Pada tahap ekstraksi, metanol berfungsi menarik senyawa-senyawa polar yang larut di dalamnya sedangkan ekstraksi menggunakan 2 propanol (1\%) dalam heksan berfungsi menarik senyawa polar dalam 2-propanol dan senyawa non polar ke dalam heksan.

\section{Hasil Analisis Konsentrasi Vitamin E dengan Metode Spektrofotometri UV- Vis}

Penentuan panjang gelombang maksimum harus dilakukan sebelum analisa meskipun beberapa penelitian telah dilakukan dalam penentuan panjang gelombang maksimum. Hal ini disebabkan preparasi sampel dan kondisi alat serta lingkungan disetiap penelitian berbeda. Berdasarkan spektrum vitamin E (Gambar 2) diperoleh titik tertinggi kurva ialah pada panjang gelombang $298,5 \mathrm{~nm}$.

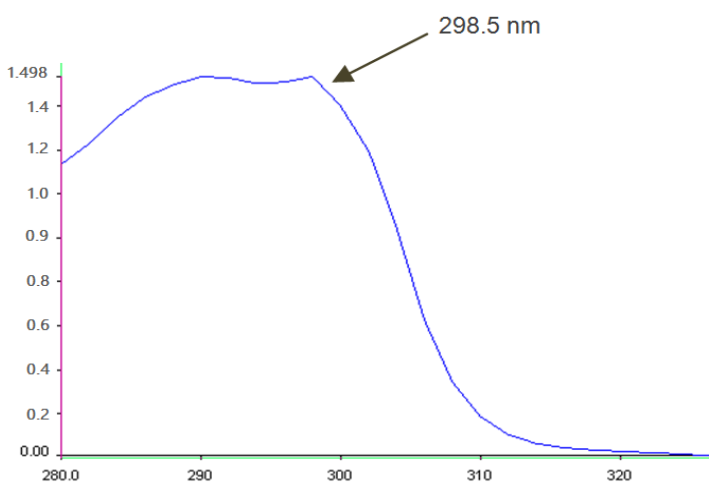

Gambar 2. Spektrum Larutan Standar Vitamin E pada Penentuan Panjang Gelombang Maksimum

Penggunaan heksan sebagai pelarut dan blanko disebabkan karena heksan merupakan pelarut yang tidak berwarna dan tidak mengandung ikatan rangkap pada struktur molekulnya sehingga tidak akan mengganggu analisis vitamin $\mathrm{E}$ juga sifatnya yang non-polar baik untuk melarutkan vitamin $\mathrm{E}$ yang juga bersifat non-polar.

Meskipun sampel yang dianalisis berwarna namun senyawa vitamin $E$ dapat menyerap radiasi pada panjang gelombang UV. Hal ini disebabkan vitamin $E$ memiliki gugus fungsi yang disebut gugus kromofor sehingga senyawa ini dapat menyerap radiasi pada panjang gelombang UV.

Nilai absorbansi sampel yang teramati pada panjang gelombang maksimum ialah 2,9736. Nilai absorbansi sampel diplotkan ke dalam persamaan linear sehingga diperoleh konsentrasi vitamin E sebesar 104,5 ppm.

\section{Hasil Analisis Konsentrasi Vitamin E dengan Metode KCKT}

Pada analisis KCKT ini tidak dilakukan pengukuran panjang gelombang maksimum dan pemilihan laju alir karena metode yang dipakai sudah tervalidasi dan sering digunakan dimana panjang gelombang yang digunakan yaitu $290 \mathrm{~nm}$ dengan laju alir $1 \mathrm{ml} /$ menit.

Berdasarkan kromatogram dapat diketahui adanya vitamin $\mathrm{E}$ dalam sampel dengan cara membandingkan waktu retensi sampel yang diduga merupakan vitamin $\mathrm{E}$ dengan larutan standar vitamin E. Berdasarkan kromatogram (Gambar 3 dan 4) dapat dilihat bahwa waktu retensi sampel maupun 7 seri larutan standar 
relatif sama yaitu untuk sampel 21,928 menit sedangkan untuk larutan standar waktu retensi rata-rata yaitu 21,668 menit dengan waktu analisis kurang dari 25 menit. Sementara itu, waktu retensi antara sampel dan standar memakan waktu relatif lama. Hal ini disebabkan penggunaan kolom fasa terbalik (RP) dimana fasa gerak yang digunakan ialah senyawa polar sedangkan fase diam adalah non-polar. Senyawa yang bersifat polar akan lebih dulu terelusi mengikuti fase gerak yang polar sedangkan vitamin E yang merupakan senyawa non-polar akan terelusi paling akhir karena terjerap pada fase diam yang bersifat non-polar.

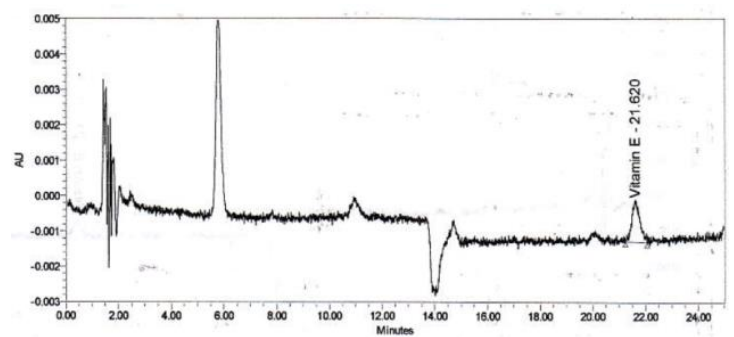

Gambar 3. Kromatogram Standar Vitamin E

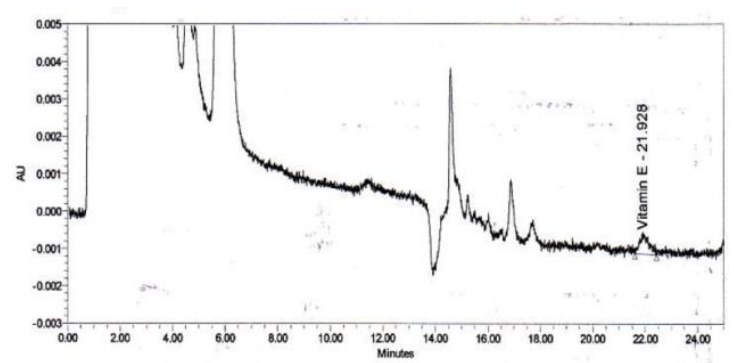

Gambar 4. Kromatogram Sampel

Setelah diperoleh persamaan kurva kalibrasi, maka dapat dilakukan perhitungan dengan memplotkan nilai luas area sampel ke dalam sebuah persamaan. Berdasarkan hasil perhitungan diperoleh konsentrasi vitamin E sebesar 127 ppm

\section{Perbandingan Hasil Analisis Konsentrasi Vitamin E antara Metode Spektrofotometri UV-Vis dan KCKT}

Prinsip dasar antara metode Spektrofotometri UV-Vis dengan metode KCKT berbeda. Metode Spektrofotometri UV-Vis memiliki prinsip dasar absorbansi, sedangkan untuk KCKT memiliki prinsip dasar kromatografi. Namun detektor KCKT yang digunakan pada penelitian ini menggunakan detektor UV-Vis yang prinsipnya sama dengan Spektrofotometri UV-Vis yaitu pengukuran didasarkan pada absorbansi pada dua rentang panjang gelombang yaitu panjang gelombang sinar ultraviolet dan pada panjang gelombang sinar tampak.

Panjang gelombang maksimum yang diperoleh pada KCKT ialah $290 \mathrm{~nm}$ sedangkan panjang gelombang maksimum pada spektrofotometri UV-Vis ialah 298,5 nm yang keduanya masih berada pada rentang panjang gelombang UV. Panjang gelombang maksimum ini relevan dengan beberapa penelititan yang pernah dilakukan yaitu panjang gelombang maksimum vitamin $\mathrm{E}$ berada pada rentang 290-300 nm (Hossu et al., 2009; Martha et al., 2012; Lampi, 2013). Diasumsikan bahwa perbedaan panjang gelombang maksimum ini disebabkan perbedaan pelarut yang digunakan untuk melarutkan standar, dimana pelarut KCKT yang digunakan ialah metanol sedangkan pada spektrofotometri UV-Vis pelarutnya adalah n-heksan. Selain itu, perbedaan instrumen yang digunakan juga diprediksi 
menyebabkan perbedaan panjang gelombang maksimum.

Berdasarkan hasil penelitian yang telah dilakukan metode spektrofotometri menghasilkan kadar vitamin $\mathrm{E}$ yang relatif mendekati dengan hasil KCKT dengan selisih konsentrasi 22,5 ppm. Pada penelitian ini, hal tersebut disebabkan karena sampel yang dianalisis mengalami perlakuan pendahuluan yang sama antara metode KCKT dan spektrofotometri UVVis yaitu dengan cara saponifikasi dan ekstraksi.

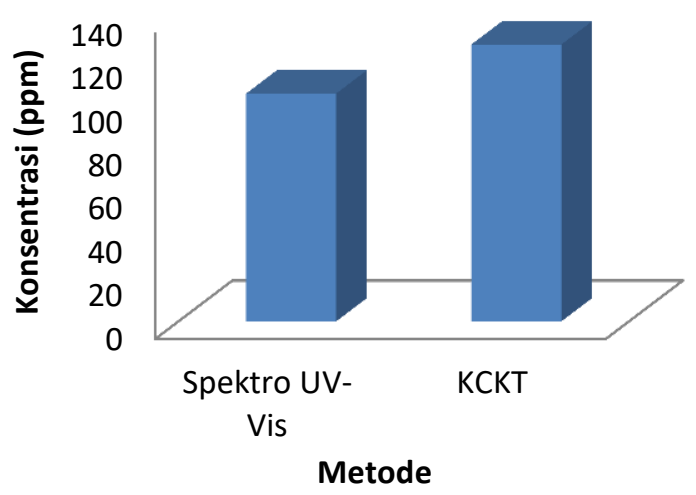

Gambar 5. Perbandingan konsentrasi vitamin E antara metode Spektrofotometri UV-Vis dan KCKT

Berdasarkan hasil penelitian yang dilakukan oleh Han \& Choo (2012) dan Lampi (2013), panjang gelombang maksimum vitamin $E$ berkisar antara 298$300 \mathrm{~nm}$ sehingga dalam penelitian ini diasumsikan senyawa yang terserap adalah benar merupakan vitamin $E$. Meskipun demikian, kemungkinan senyawa lain yang dapat terserap pada panjang gelombang tersebut masih ada.

Perbandingan data konsentrasi sampel minyak sawit merah tersaponifikasi dari masing-masing metode pada penelitian ini disajikan dalam Gambar 5.

Meskipun hasil analisis konsentrasi vitamin E antara metode Spektrofotometri UV-Vis dengan metode KCKT cenderung mendekati, namun bukan berarti dapat diklaim bahwa kandungan vitamin $E$ secara kuantitatif adalah valid karena sejauh ini belum ada laporan yang membuktikan tentang analogi kedua metode tersebut yang divalidasi dengan metode penetuan struktur- IR, Spektrofotometer Massa dan RMI. Meskipun demikian adanya pendekatan metode yang dilakukan seperti serapan panjang gelombang pada Spektrofotometer UV-Vis dan KCKT mengindikasikan bahwa adanya kandungan vitamin $\mathrm{E}$ yang dapat dianalisis secara kuantitatif.

\section{KESIMPULAN}

Konsentrasi vitamin E yang dianalisis menggunakan KCKT ialah 127 ppm sedangkan konsentrasi sampel yang dianalisis menggunakan metode Spektrofotometer UV-Vis sebesar 104,5 ppm.

\section{UCAPAN TERIMA KASIH}

Secara khusus peneliti menyampaikan ucapan terima kasih kepada Prof. DR. H. Mappiratu, MS.

\section{DAFTAR PUSTAKA}

Bonnie T.Y.P., Choo, Y.M. 2000. Practical guide to establishing palm carotenoids profile by HPLC with three dimensional diode array 
detector. Palm Oil Development, 33 : 13-17

Choo YM., AN Ma., CK Ooi., SC Yap., Y Basiron. 1993. Red Palm Oil acarotene rich nutritious oil. PORIM Information Series No. 11 : Palm Oil Research. Institute of Malaysia

Dauqan E., Sani HA., Abdullah A., Muhamad H., Gapor AM. 2011. Vitamin $E$ and Beta Carotene Composition in Four Different Vegetable Oils. American Journal of Applied Sciences 8 (5): 407-412

ESA Analytical. 2002. Determination of tocopherol and tocotrienols, Aplication Note, ESA, Inc, Chelmsford, USA

Han NM., Choo, YM. 2012. Chromatographic Analysis of Tocopherols and Tocotrienols in Palm Oil. Jurnal Of Chromatography Scie. $50: 283-286$

Hossu, Ana-Maria., C Radulescu, M Ilie. Berlin. 9-11 October 2006. International Symposium for High Performance Thin Layer Chromaography : TLC analysis of pharmaceutical preparations containing vitamins $A, D$ and $E$

Kresnawaty I., Budiani, A., Tri-Panji dan Suharyanto. 2012. Isolasi dan mikroenkapsulasi vitamin $\mathrm{E}$ dari crude palm oil sebagai sumber antioksidan bahan pangan. $J$. Menara Perkebunan. 80(2) : 68-76

Lampi AM. 2013. Analysis of Tocopherols and Tocotrienols by HPLC. Department Of Food and Environmetal Science. Finland: University Of Helsinky.

Martha SA., FF Karwur, FS Rondonuwu. 2012. Metode Purifikasi Vitamin E Dari Minyak Kelapa Sawit. In :
Seminar Nasional $X$ Pendidikan Biologi FKIP UNS

Ooi CK., Choo, YM., Ong, ASH. 1991. Recovery of Carotenoids, US Patent No. 5019668

Rohman, Abdul. 2007. Kimia Farmasi Analisis, Pustaka Pelajar, Yogyakarta

Ryynanen M., Lampi, A., Salo-Vaananen, P., Ollilainen, $V$ and Piironen, $V$. 2004. A small-scale sample preparation method with HPLC analysis for determination of tocopherols and tocotrienols in cereals. J Food Comp Anal. 17 : 749-765

Świglo AG., Sikorska, E., Khmenlinskii, I and Sikorski, M. 2007. Tocopherol content in edible plants oil, Polish $\mathrm{J}$ Food Nutr Sciences. 57 : 157-161. 